\title{
EFFECT OF GAMMA IRRADIATION ON SURVIVABILITY, GROWTH PERFORMANCES AND FLORAL CHARACTERS OF Jasminum officinale (Samanpichcha)
}

\author{
Nelka S.A.P. ${ }^{*}$, Vidanapathirana N.P. ${ }^{1}$, Dahanayake N. ${ }^{2}$, Subasinghe S. ${ }^{2}$, Silva T.D. ${ }^{3}$, Weerasinghe S. ${ }^{1}$, Rifnas L.M. ${ }^{1}$, \\ Rohanadeera H. ${ }^{1}$, Madushanka W.C.M.S. ${ }^{1}$, Dushane S. ${ }^{1}$, Dhanushka T.G.B. ${ }^{1}$, Anuruddhi H.I.G.K. ${ }^{1}$ \\ ${ }^{1}$ University of Colombo Institute for Agro-Technology and Rural Sciences, Hambantota, Sri Lanka \\ ${ }^{2}$ Faculty of Agriculture, University of Ruhuna, Mapalana, Kamburupitiya, Sri Lanka \\ ${ }^{3}$ Department of Plant Science, Faculty of Science, University of Colombo, Sri Lanka \\ *Corresponding Author: nelka@uciars.cmb.ac.lk (https://orcid.org/0000-0001-5575-8976) \\ Received: 29.09.2021; Accepted: 28.10.2021; Published: 05.11.2021
}

\begin{abstract}
Physical mutagenesis is an effective mutational breeding method for improving various growth and floral characteristics of ornamental plants. The experiment was undertaken with an objective to investigate the effect of various dosages of gamma irradiation on survivability, growth and floral characteristics of Jasminum officinale plants raised by rooted cuttings. The ${ }^{60} \mathrm{CO}$ Gamma irradiation source at Horticultural Crop Research and Developmental Institute, Gannoruwa was used to expose rooted plants to different dosages such as 0Gy, $17 G y, 21 G y, 25 G y, 29 G y$ and 33Gy. A Complete Randomized Design with four replicates having 10 plants for each replicate was practiced. The results revealed that gamma irradiation dosage from 25Gy to $33 G y$ significantly decreased the survivability of $J$. officinale plants $(P<0.05)$. LD $D_{50}$ of gamma radiation on $J$. officinale was occurred around 33Gy at maturity stage. Plant height and shoot length were significantly reduced by gamma irradiation dosages of $17 \mathrm{~Gy}$ to $33 \mathrm{~Gy}$ compared to the control and significant reduction of shoot number was observed at 33Gy. Gamma irradiation with 17 Gy dosage, it showed a significant reduction in petal width $(0.82 \mathrm{~cm})$ of flowers. None of the other dosages were able to develop a change in the floral characteristics of J. officinale. The study showed that 33Gy gamma irradiated plant, it is having significant reduction of plant height, number of shoots and shoot length hence it could be domesticated as a dwarf and potted plant.
\end{abstract}

\section{Keywords: Dosage, Gamma irradiation, Jasminum officinale, Rooted cuttings, Survivability}

\section{INTRODUCTION}

Jasminum officinale (Samanpichcha) is one of the most demanding indigenous flower species in Sri Lanka which is belonging to the family Oleaceae. The genus consists with around 200 species. This plant is used for perfume industry as a flavoring agent and various cosmetics and medicinal purposes.

When considering this plant as a floriculture crop, it has a limited variation of plant and flower characteristics as this plant is a vegetatively propagated plant. Therefore, creating a variation through induced mutagenesis is more important to promote this plant as a home gardening plant around Sri LankaGenerally, physical and chemical mutagen were used to produce new varieties with better characteristics of their genetic variation (Kaushik., et. al., 2015). Properties of mutagens, treatment duration, pre and post treatments, and temperature are the several influencing factors for effectiveness of mutagens. In any mutagenesis method, the dose of applying the mutagen is an important factor. It was noticed that the greater biological damage observed at higher concentration of mutagens (Rajib and Jagatpati, 2011).

Therefore, the present experiment was carried out to study the effect of different dosages of gamma irradiation on survivability, growth performances and floral characteristics of Jasminum officinale.

\section{METHODOLOGY}

\section{Experimental Site}

The experiment was conducted during the period of June 2020 to October 2020 at the Institute for Agro- technology and Rural Science, University of Colombo, Weligatta, Hambantota located in Dry Zone of Sri Lanka where the mean annual rain fall is $1250 \mathrm{~mm}-1500 \mathrm{~mm}$ and mean annual temperature 
is $29^{\circ} \mathrm{C}-33^{\circ} \mathrm{C}$. Soil types of the area are Reddish Brown Earth and Low Humic Gley soil.

\section{Planting materials}

Four months old healthy, $8 \mathrm{~cm}$ height Jasmin plants, were used for the study. All plants were raised as shoot tip derived cuttings in $5 \mathrm{~cm}$ height $\times 4 \mathrm{~cm}$ width poly bag containers filled with sand: compost 1:1 (v/v) media.

\section{Gamma irradiation}

Jasminum officinale potted plants were treated with gamma radiation at Horticultural Crops Research and Development Institute (HORDI), Gannoruwa, Sri Lanka. ${ }^{60}$ Cobalt Gamma irradiator source was used to treat the plants and five gamma ray doses (17Gy, 21Gy, 25Gy, 29Gy and 33Gy) were selected as treatments.

\section{Post treatment cultural practices}

Treated plants were established in $12.5 \mathrm{~cm}$ height $x$ $10 \mathrm{~cm}$ width black poly bag containers with 250 gauge and filled with sand: compost $1: 1(\mathrm{v} / \mathrm{v})$ media. Plants were kept under a shade house and maintained under uniform conditions provided with equal irrigation using a measuring can. Subsequently, the growing plants were transferred to $30 \mathrm{~cm}$ diameter pots with topsoil: sand: compost $1: 1: 1(\mathrm{v} / \mathrm{v})$ media at 8 weeks after the treatment as they were starting to produce new shoots and not enough the small pot for further growth and development.

\section{Evaluation of survivability, growth, and yield performances of treated plants}

The data recorded were used to calculate the percentage of survival at six months that is at their maturity. It was calculated for each treatment as the ratio of alive (survived) plants to the total number of plants treated and established.

Survival $\%=($ No. of survived plants/ No. of gamma irradiated plants) $\times 100$

The plant growth parameters: plant height and shoot length were recorded using the measuring tape in $\mathrm{cm}$ and number of shoots were recorded by counting. Petal length, petal width, flower diameter and stalk length all in $\mathrm{cm}$ were recorded using a foot ruler and a vernier caliper at the flowering stage as flower characters.

\section{Experimental design and Statistical analysis}

The experimental design was Completely Randomized Design (CRD) with 5 treatments excluding non-treated plants as the control. Four replicates per treatment were maintained with 10 plants per each replicate accounting total of 40 plants per treatment. The data were statistically analyzed using Minitab 17 software. One- way ANOVA general linier model test was performed while Dunnett and Tukey tests were used to ascertain the significant differences among treatments at 0.05 significant level.

\section{RESULTS AND DISCUSSION}

\section{Survivability of gamma irradiated plants}

Table 1: Effects of Gamma irradiation on survivability of Jasminum officinale plants

\begin{tabular}{cc}
\hline Treatments & $\begin{array}{c}\text { Survival \% at 6 } \\
\text { after month }\end{array}$ \\
\hline 0 Gy (T0) & $97.5^{\mathrm{a}}$ \\
17 Gy (T1) & $97.5^{\mathrm{a}}$ \\
21 Gy (T2) & $90.0^{\mathrm{a}}$ \\
25 Gy (T3) & $67.5^{\mathrm{b}}$ \\
29 Gy (T4) & $60.0^{\mathrm{b}}$ \\
33 Gy (T5) & $50.0^{\mathrm{b}}$ \\
\hline
\end{tabular}

Column having same letter are not significantly difference at $p<0.05$

After six months from treatment application, no significant difference was observed in the percentage of survival of plants in gamma irradiated dosages at $17 \mathrm{~Gy}$ and $21 \mathrm{~Gy}$ with compared to the control (Table 1). But survival percentage was significantly decreased when increased the gamma irradiation rate at $25 \mathrm{~Gy}$, 29Gy and 33Gy. $\mathrm{LD}_{50}$ value was calculated according to the 50 percent survival rate in maturity stage of J. officinale after exposing the gamma irradiation as $33 \mathrm{~Gy}$. The reduction of the survivability after the gamma irradiation may be due to the drop of auxin level resulting the poor establishment and chromosome aberrations created by mutagenic treatments. A study of Broerjest et. al., (2013), explained the substantial damage of meristematic cells and essential plant cell components at the physiological level of plants exposed to higher doses of gamma rays. The study carried out by Ghosh et. al., in 2018 reported that survival percentage of gamma treated cuttings ranging from 5Gy to 40Gy of different Jusminum species is varied with the species and recorded that LD50 value as $17.8 \mathrm{~Gy}$ in J. grandiflorum, 28Gy in $J$. multiflorum and $25.1 \mathrm{~Gy}$ in $J$. nitidum. 
According to Rifnas et. al., (2020) a higher survival rate of Allamanda cathartica was observed in first few months of treated plants and when the plants are matured the dead plant number was increased. He also has explained that it is due to the damage of plant tissues and breakdown of meristem cells in the plants.

\section{Growth performances of gamma irradiated plants}

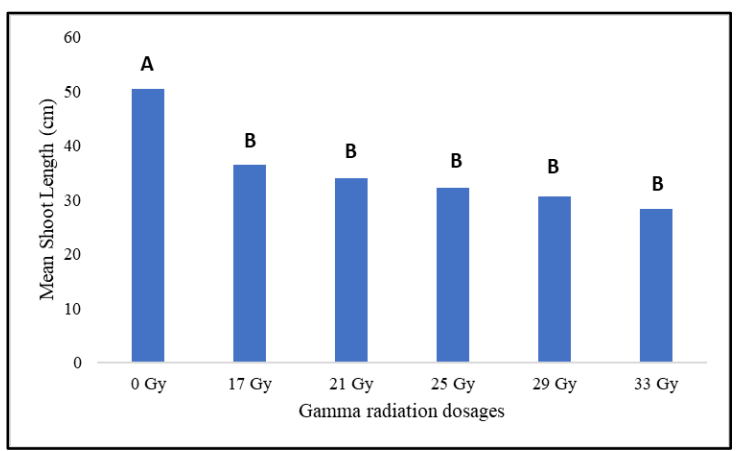

Figure 1: Effect of Gamma irradiation on plant height

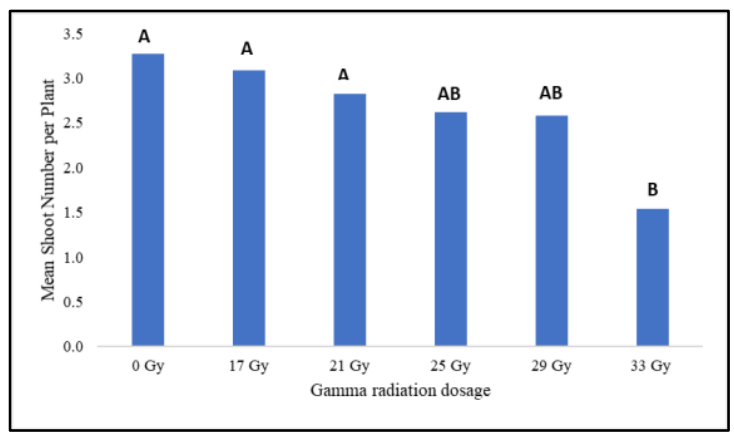

Figure 2: Effect of Gamma irradiation on number of shoots per plant

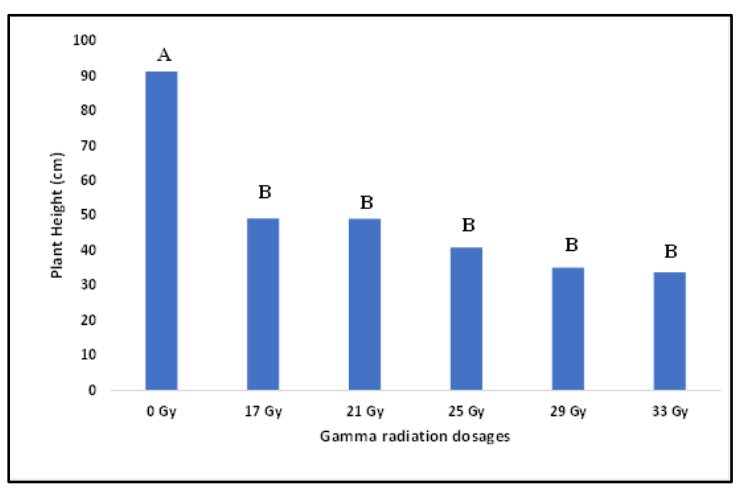

Figure 3: Effect of Gamma irradiation on shoot length

The results of effect of gamma radiation dosages on different growth parameters of J. officinale are represented in the Fig. 1, Fig. 2 and Fig. 3. These results showed that plant height (Figure 1), number of shoots (Figure 2) and shoot length (Figure 3) were significantly responded to the various irradiation treatments. It is interesting to note that the irradiation treatments have significantly reduced the plant height compared to the control plants $(\mathrm{P}<0.05)$ but among the treated plants, no significant difference was observed. The results revealed that the mean plant height ranged from $49.27 \mathrm{~cm}$ (17Gy) to $33.79 \mathrm{~cm}$ (33Gy) and the control recorded the maximum plant height as $91.2 \mathrm{~cm}$. Accordingly, 33Gy gamma irradiated plant has a considerable difference of its plant height with the control plant (Plate 1 to 6). Reduction of plant height is an advantageous character for an ornamental plant regardless of the gamma dosage. This retardation of plant height could be due to the effect of radiation on cells in apical buds and it may cause to decrease or inhibit the auxin content produced by those cells which restricts the elongation.

Ghosh et. al., (2020) has reported that, exposing the terminal cuttings of Jasminum grandiflorum to the gamma radiation doses ranging from 10-25 Gy has responded in plant growth parameters such as plant height, number of primary branches and leaf area. The variation was reduced with increase in gamma radiation dosage from $10 \mathrm{~Gy}$ to $25 \mathrm{~Gy}$. According to their study the highest mean plant height $(51.99 \mathrm{~cm})$ was recorded in the lower gamma dosage of 10Gy and the lowest mean plant height $(47.77 \mathrm{~Gy})$ was recorded in 25Gy gamma dosage. Further they mentioned that the reason for progressive reduction of plant height is inactivating of auxin and decrease its content with the increasing of gamma ray dosages.

Previous studies showed that majority of the species which poses a reduction of plant height with gamma ray irradiations have been subjected to seed treatments rather than rooted cuttings/ plants. As stated by Pallavi et. al., (2017), decrease in the activity of meristematic tissue mitotic division as well as a decrease in the moisture content of the seeds develops dwarf plants. Therefore, we can suggest that the reduction of plant height depends on the planting material (seeds or rooted cuttings) used for irradiation.

Mean number of shoots per plant (Figure 2) also significantly affected by gamma irradiation treatments. The results shown that the mean shoot number (3.1) was recorded in 17Gy treatment, and the lowest mean shoot number (1.5) was recorded in 33Gy treatment while control having the highest mean shoot number (3.3). Significant reduction of shoot number per plant was observed only in 33Gy treatment when compared to the control and all other treatments in the experiment. 


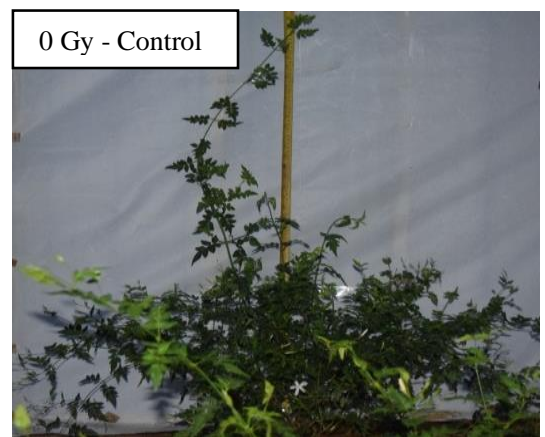

Plate 1: Vegetative growth of control plant (MPH:91.2cm)

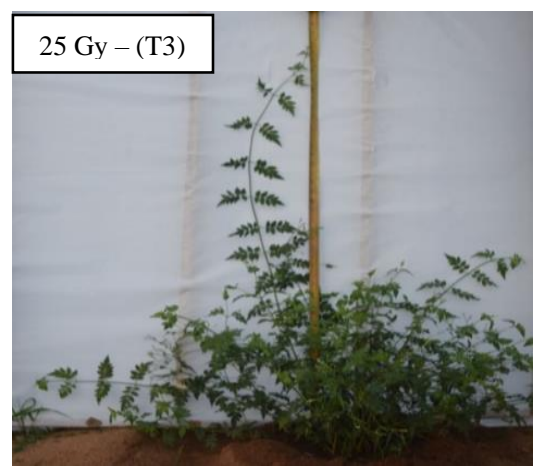

Plate 4: Vegetative growth of 25Gy (T3) plant (MPH:40.86cm)

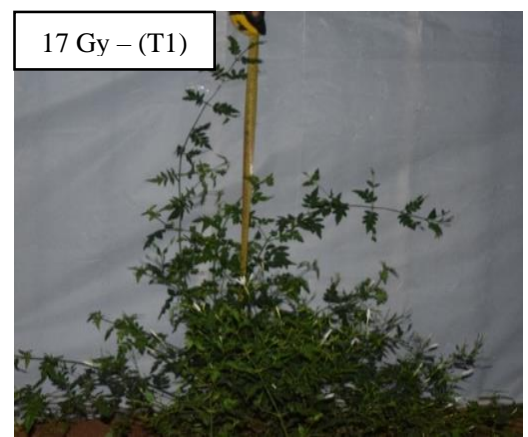

Plate 2: Vegetative growth of $17 \mathrm{~Gy}$ (T1) plant (MPH:49.27cm)

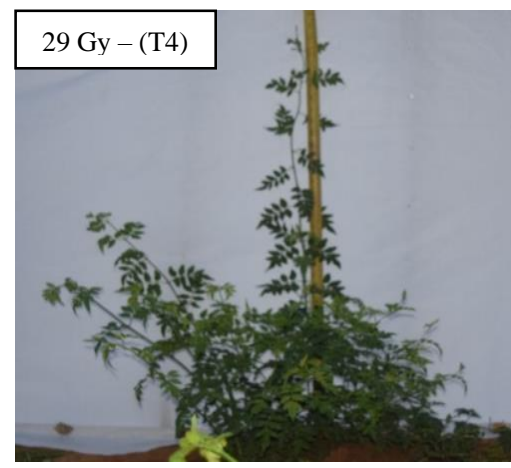

Plate 5: Vegetative growth of 29Gy (T4) plant (MPH:35.17cm)

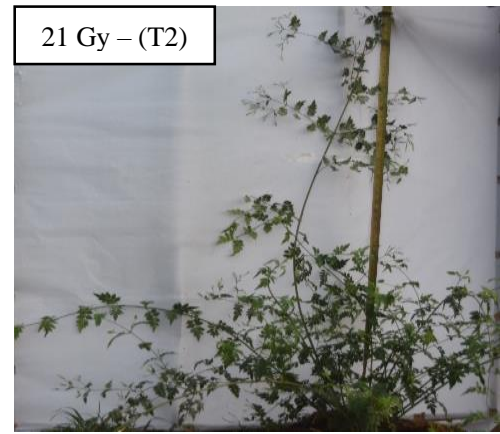

Plate 3: Vegetative growth of $21 \mathrm{~Gy}$ (T2) plant (MPH: $49.08 \mathrm{~cm}$ )

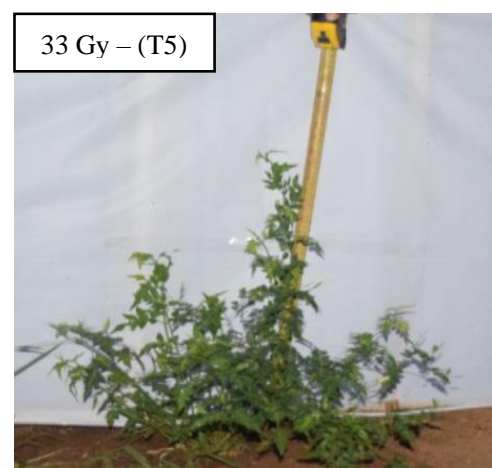

Plate 6: Vegetative growth of $33 \mathrm{~Gy}$ (T5) plant (MPH:33.79 cm)

Note: MPH - Mean Plant Height
This difference may be due to the restriction of multiplication of active cells that suppress the shoots development in 33Gy plants. A study of Gosh et. al., (2020) reported that the mean number of primary branches lower (2.78) in $25 \mathrm{~Gy}$ and higher (3.98) in 15Gy when exposure Jusminum grandiflorum cuttings for gamma irradiation. According to the findings of Aisyah et. al., in 2005, survival rate, plant height and shoot number were reduced when exposures the rooted cutting plants of different Jasminum species to the gamma irradiation dosages of 50Gy and 55Gy. With the present study, It could be suggested that, lower plant height and less ability to initiate the higher number of shoots, 33Gy plant is appeared as a dwarf plant and it is better to domesticated as a potted plant in home gardening.

Further, gamma irradiation has significantly affected on shoot length (Figure 3) of J. officinale rooted cutting plants $(\mathrm{P}<0.05)$. Shoot length of all gamma irradiated plants was significantly decreased when compared to the control plants. Mean shoot length was recorded as $36.4 \mathrm{~cm}$ in $17 \mathrm{~Gy}$ and the lowest mean shoot length was
$28.4 \mathrm{~cm}$ in $33 \mathrm{~Gy}$ gamma dosage while control having the highest mean shoot length of $50.4 \mathrm{~cm}$. There was no any significant difference observed among the treatments from $17 \mathrm{~Gy}$ to $33 \mathrm{~Gy}$. The mean shoot length per plant shows a decreasing pattern parallel to the plant height. The explanation from Ghosh et. al., in 2018 supported to prove these results the influencing of mutagenic agent as an inhibitor for vegetative growth performances such as shoot length, number of leaves and leaf length can be shown a decreasing pattern with the increasing of gamma irradiation dosage (5Gy to 40Gy) on Jasminum spp and Kannan, (1994) mentioned that J. sambac is a woody perennial plant which is inhibitory influence of ionizing radiation was well established.

However, when considering all above three parameters such as plant height, number of shoots per plant and shoot length, there is a high potential to domesticate 33Gy gamma irradiated plant as a dwarf potted plant as an value addition for traditional Jasminum officinale in home gardening.

Lack of information availability of previous studies could not find much similar or various results 
regarding the gamma irradiation on J. officinale or on family Oleaceae. But some cases were reported on other crops in gamma irradiation. In 2004, Toker and Cagirgan reported that higher dosages of gamma irradiation in between 200Gy to 400Gy are affected to reduce the shoot length of seed germinated plants in chickpea. Tocker et. al., (2005) concluded that critical dosage for shoot and root elongation is varying among the species and in different genotypes in same species.

\section{Flower yield and flower characteristics of gamma irradiated plants}

Mean flower yield was not significantly affected by used gamma irradiation dosages ranging from $17 \mathrm{~Gy}$ to $33 \mathrm{~Gy}$ in J. officinale ( $\mathrm{P}>0.05)$. Ghosh et. al., (2020) reported that in gamma irradiated J. grandiflorum plants ranging from $10 \mathrm{~Gy}$ to $25 \mathrm{~Gy}$ had not observed a significant change in flower yield and no increasing or decreasing trend followed by flower yield with the gamma ray dosages.

The results revealed that none of the used gamma irradiation doses for the experiment from $17 \mathrm{~Gy}$ to 33Gy were enough to develop a significant change in considered floral characteristics (stalk length, bud length, petal length and flower diameter) of $J$. officinale $(\mathrm{P}>0.05)$ except the petal width. The petal width of flowers in $17 \mathrm{~Gy}$ gamma irradiated plants showed a significant reduction $(\mathrm{P}<0.05)$ of their petal width $(0.83 \mathrm{~cm})$ when compared to the control $(1 \mathrm{~cm})$. This reduction of petal width caused by lower concentration of gamma ray dosage (17Gy) may be due to the inhibitory influence on cell division and elongation. The used gamma irradiation range from $17 \mathrm{~Gy}$ to $33 \mathrm{~Gy}$ may be not strong enough to produce any mutagenetic change on floral characters in J. officinale rooted cutting plants. A study on Jasminum spp. Aisyah et al., (2005) has indicated that, when exposing the rooted cutting plants to gamma radiation dosages with 50 and 55Gy, it was affected the flowering period, reduced flower size, petiole length, stalk length, petal number and calyx number but did not observe any change in flower colour and aroma in all tested Jasminum species. Further he concluded that, 50Gy gamma ray dosage can create much frequent mutant than 55Gy gamma ray dosage in different Jasminum species.

\section{CONCLUSIONS}

It can be concluded that the higher dosages of gamma irradiations significantly decrease the survivability of Jasminum officinale rooted cuttings. $\mathrm{LD}_{50}$ of gamma radiation on J. officinale occurred as $33 \mathrm{~Gy}$ at maturity stage. Vegetative growth on plant height and shoot length of $J$. officinale are significantly reduced with the gamma irradiation dosages of $17 \mathrm{~Gy}, 25 \mathrm{~Gy}, 29 \mathrm{~Gy}, 33 \mathrm{~Gy}$ and significant reduction of number of shoots was occurred at 33Gy. Gamma irradiation dosages from $17 \mathrm{~Gy}$ to $33 \mathrm{~Gy}$ were not enough to develop a change in the floral characteristics of stalk length, bud length, petal length, flower diameter of $J$. officinale and only the 17Gy gamma dosage was significantly affected for the reduction of petal width. Gamma irradiated plants in 33Gy have potential to develop as a domesticated dwarf potted plant of $J$. officinale since this dosage induced the smaller number of shoots, less plant height and less shoot length when compared to the control plants.

Hence it could be recommended that exposing the Jasminum officinale plants to the gamma irradiation dosages above 33Gy has the potential to generate attractive mutants but with reducing the mortality rate.

\section{ACKNOWLEDGEMENTS}

This research was supported by the Accelerating Higher Education Expansion and Development (AHEAD) Operation of the Ministry of Higher Education funded by the World Bank. Also Mr. R.M.J.C.C. Senanayake, Radiation Safety Officer at Horticulture Crop Research and Development Institute, Gannoruwa gave the fullest support to provide the irradiation facilities.

\section{REFERENCES}

Aisyah, S.I., Hapsari, L. and Herlina, D. 2005. Induced mutation on jasmine (Jasminum spp.) through gamma irradiation. Journal of Agriculture and Rural Development in the Tropics and Subtropics Beheift, 83, pp.120-127.

Datta S.K., Misra P. and Mandal A.K.A. 2005. In vitro mutagenesis - a quick method for establishment of solid mutant in chrysanthemum. - Curr. Sci., 88(1): 155-158.

Datta, S.K. and Chakraboty, D. 2009. Management of chimera and in vitro mutagenesis for development of new flower color/shape and chlorophyll variegated mutants in Chrysanthemum, pp. 303-305. - In: SHU Q.Y (ed.) Induced plant mutations in the genomics era. Food and Agriculture Organization of the United Nations, Rome, Italy, pp. 460.

Ghosh, S., Ganga, M., Soorianathasundaram, K., Kumar, A. and Kapoor, M. 2020. Induction of 
mutation in Jasminum grandiflorum with gamma rays and EMS and identification of novel mutants using molecular markers and SEM imaging. Indian Journal of Horticulture, 77(4), pp.695-703.

Ghosh, S., Ganga, M. and Soorianathasundaram, S.K. 2018. Research Article Determination of radio sensitivity of jasmine (Jasminum spp.) to gamma rays. Electronic Journal of Plant Breeding. 9. 10.5958/0975-928X.2018.00119.9.

Kannan, M. 1994. Studies on induced mutation in Jasminum sambac cv. Gundumalli through mutation breeding. Ph.D thesis submitted at Tamil Nadu Agricultural University, Coimbatore, Tamil Nadu, India.

Kaushik, K.P., Baisakh, B., Mohanty, A. and Pradhan, J. 2015. Mutagenic Efficiency and Effectiveness of Gamma Rays, Ethyl Methane Sulphonate (EMS), Nitrosoguanidine (NG) and Their Synergistic Effect for Different Polygenic Traits in Black Gram (Vigna Mungo (L.) Hepper) Through Induced Mutagenesis. International Journal of Plant, Animal and Environmental Sciences. 5. 292-297.

Magdalita, P.M., De Leon, M.J.C., Sotto, R.C. and Ponce, K.S. 2013. Occurrence of pigmented flowers and variation in other morphological traits of irradiated and unirradiated sampa guita (Jasminum sambac L. Sol.). Journal of Nature Studies. 12(2), pp.45-53.

Pallavi, B., Nivas, S.K., D'souza, L., Ganapathi, T.R. and Hegde, S. 2017. Gamma rays induced variations in seed germination, growth and phenotypic characteristics of Zinnia elegans var. Dreamland. Advances in Horticultural Science, 31(4), pp.267-2.

Rajib, R., and Jagatpati, T. 2011. Assessment of Chemical Mutagenic Effects in Mutation Breeding programme for M1 generation of Carnation (Dianthus caryophyllus). Research in Plant Biology (ISSN: 2231-5101). 1. 23-32).

Rifnas, L.M., Vidanapathirana, N.P., Silva, T.D., Dahanayake, N., Weerasinghe, S.S. and Subasinghe, S. 2020. Effect of gamma radiation on survival rate of Allamanda cathartica-An indigenous medicinal plant. International Journal of Minor Fruits, Medicinal and Aromatic Plants, 6(1), pp.50-53.

Toker, Cengiz. 2004. Evaluation of yield criteria with phenotypic correlations and factor analysis in chickpea. Acta Agriculturae Scandinavica Section B-soil and Plant Science - ACTA AGR SCAND SECT B-SOIL PL. 54. 45-48. 10.1080/09064710310022023.

Toker, Cengiz., Uzun Bülent., Canci Huseyin. And Ceylan Fatma. 2005. Effects of gamma irradiation on the shoot length of Cicer seeds. Radiation Physics and Chemistry - RADIAT
PHYS CHEM. $73 . \quad 365-367$. 10.1016/j.radphyschem.2005.03.011 